\title{
Kleptomania in Patients with Neuro-Behçet's Disease
}

\author{
Erkingül Shugaiv $^{b}$ Aslı Kıyat-Atamer ${ }^{a}$ Erdem Tüzün $^{d}$ Murat Kürtüncü ${ }^{b}$ \\ Işın Baral-Kulaksızoğluc Gülşen Akman Demir a, b \\ ${ }^{a}$ Department of Neurology, School of Medicine, Istanbul Bilim University, ${ }^{b}$ Department of Neurology and \\ 'Department of Psychiatry, Istanbul Faculty of Medicine, and d Department of Neuroscience, Institute of \\ Experimental Medicine and Research, Istanbul University, Istanbul, Turkey
}

\section{Key Words}

Neuro-Behçet's disease - Meningoencephalitis .

Kleptomania $\cdot$ Impulse control disorder

\begin{abstract}
Objective: This study was conducted to characterize the prevalence and clinical features of kleptomania, an impulse control disorder, in patients with Behçet's disease involving the central nervous system. Subjects and Methods: Medical records of 350 patients with neuro-Behçet's disease were evaluated, and clinical and neuropsychological features of patients with kleptomania were noted. Results: Of the 350 neuro-Behçet's disease patients $6(1.7 \%)$ had presented with symptoms that fulfilled the criteria of kleptomania according to the revised 4th version of the Diagnostic and Statistical Manual of Mental Disorders. The 6 patients ( 5 men, 1 woman) had parenchymal lesions and had developed kleptomania during remission. Magnetic resonance imaging done on the 6 patients before the onset of kleptomania mostly revealed brainstem lesions. Psychiatric assessment did not show any comorbid psychiatric disorders and neuropsychological
\end{abstract}

evaluation showed executive dysfunction in all patients. Conclusion: The 6 patients with kleptomania had developed a frontal lobe syndrome.

Copyright $\odot 2013$ S. Karger AG, Basel

\section{Introduction}

Behçet's disease is a multisystemic, relapsing, autoinflammatory disorder of unknown origin [1-3]. Clinical manifestations of this disorder include recurrent oral aphthae, genital ulcers, erythema nodosum, pseudofolliculitis, uveitis and arthritis. Involvement of the central nervous system is seen in $5-15 \%$ of patients [1]. These patients mostly develop brainstem meningoencephalitis and in $15-20 \%$ of patients with neurological disorders dural sinus thrombosis occurs [1].

The neurological manifestation of neuro-Behçet's disease may include a variety of syndromes, and psychiatric disorders may be seen, either solely or in combination with other dysfunctions [1]. Cognitive deficits, apathy, acute psychosis, personality and behavioral disorders are

\begin{tabular}{ll}
\hline KARGER & $\begin{array}{l}\text { ○ 2013 S. Karger AG, Basel } \\
1011-7571 / 13 / 0226-0550 \$ 38.00 / 0 \quad \text { Karger }\end{array}$ \\
E-Mail karger@karger.com & $\begin{array}{l}\text { This is an Open Access article licensed under the terms of the } \\
\text { Creative Commons Attribution-NonCommercial 3.0 Un- } \\
\text { ported license (CC BY-NC) (www.karger.com/OA-license), } \\
\text { applicable to the online version of the article only. Distribu- } \\
\text { tion permitted for non-commercial purposes only. }\end{array}$
\end{tabular}

Erkingul Shugaiv, MD

Department of Neurology, Istanbul Faculty of Medicine Istanbul University

TR-34093 Istanbul (Turkey)

E-Mail erkingul_sh@ @otmail.com 
Fig. 1. Axial T2-weighted images of case 4 showing bilateral lesions in upper brainstem, diencephalon and basal ganglia (arrows).

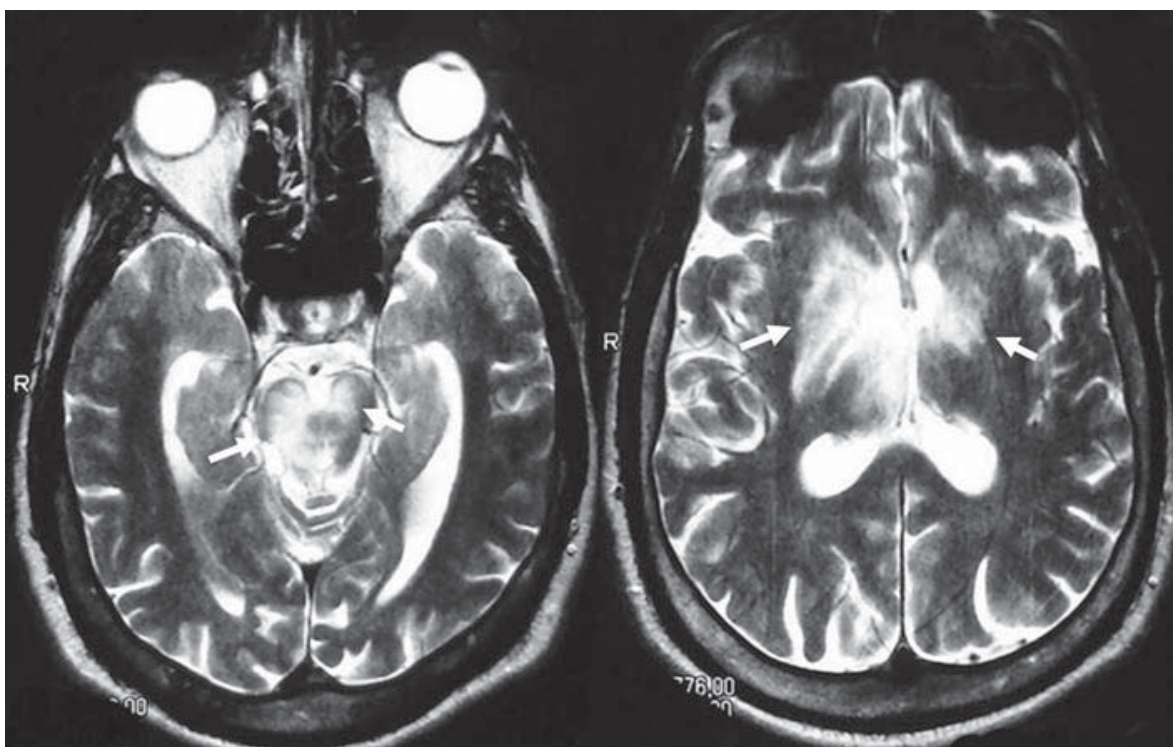

among the neuropsychiatric disorders that may accompany Behçet's disease [4].

Impulse control disorders constitute a class of psychiatric disorders characterized by failure to resist a temptation, urge or impulse that may harm oneself or others. Many psychiatric disorders feature impulsive behavior, including substance-related disorders, paraphilias, attention deficit hyperactivity disorder, antisocial personality disorder, conduct disorder, schizophrenia and mood disorders. The revised fourth edition of the Diagnostic and Statistical Manual of Mental Disorders includes the category impulse control disorders not elsewhere classified', which consists of kleptomania, pathological gambling, pyromania, trichotillomania and intermittent explosive disorder [5]. Kleptomania is defined as the failure to resist impulses to steal objects not needed for personal use or their monetary value $[6,7]$.

In this article, we present the clinical characteristics, radiological features, neuropsychological and psychiatric evaluation of patients with neuro-Behçet's disease that were diagnosed with kleptomania at some point during their disease course.

\section{Subjects and Methods}

A total of 350 neuro-Behçet's disease patients followed between 1984 and 2012 in our outpatient clinic were evaluated retrospectively. Patients who fulfilled criteria for the diagnosis of kleptomania according to the revised 4 th version of the Diagnostic and Sta- tistical Manual of Mental Disorders were determined and their neurological examination, brain magnetic resonance imaging (MRI) findings (prior to or after the development of kleptomania), psychiatric evaluation and neuropsychological assessment (during kleptomania) were recorded. The cognitive evaluation of the patients consisted of a detailed neuropsychological battery as previously described [4].

\section{Results}

\section{Demographic and Clinical Features}

Of the 350 patients with neuro-Behçet's disease, 6 $(1.7 \%)$ were identified with kleptomania. Four of these patients (cases 1, 4, 5 and 6) had reported their kleptomania symptoms during a follow-up visit, while the symptoms of the remaining 2 patients (cases 2 and 3 ) had been reported by their family members. Five kleptomania patients were male and 1 was female. Their mean age was 39.8 years (29-56). All the 6 patients had parenchymal neuro-Behçet's disease with attacks. Time between the last attack and onset of kleptomania varied from 2 months to 4 years. MRI examinations had been performed before the onset of kleptomania in all patients and after the onset of kleptomania in 1 patient (case 4). During their followup prior to development of kleptomania, all patients had developed infratentorial lesions, mainly in the pons and midbrain (fig. 1) and 2 patients had additional lesions in both basal ganglia (table 1). None of the patients had frontal, cortical or subcortical lesions. Due to absence of neurological symptoms, none of the patients except case 
Table 1. Demographic and clinical features of the patients with kleptomania

\begin{tabular}{|c|c|c|c|c|c|c|}
\hline & Case 1 & Case 2 & Case 3 & Case 4 & Case 5 & Case 6 \\
\hline Gender & $\mathrm{M}$ & $\mathrm{M}$ & $\mathrm{M}$ & $\mathrm{M}$ & $\mathrm{M}$ & $\mathrm{F}$ \\
\hline $\begin{array}{l}\text { Neuro-Behçet's disease } \\
\text { duration, years }\end{array}$ & 3 & 26 & 20 & 6 & 4 & 2 \\
\hline $\begin{array}{l}\text { MRI findings prior to } \\
\text { onset of kleptomania }\end{array}$ & $\begin{array}{l}\text { pons, } \\
\text { midbrain }\end{array}$ & $\begin{array}{l}\text { pons, } \\
\text { midbrain }\end{array}$ & $\begin{array}{l}\text { pons, basal } \\
\text { ganglia }\end{array}$ & $\begin{array}{l}\text { pons, midbrain, } \\
\text { diencephalon, } \\
\text { basal ganglia }\end{array}$ & $\begin{array}{l}\text { pons, } \\
\text { midbrain }\end{array}$ & $\begin{array}{l}\text { pons, } \\
\text { midbrain }\end{array}$ \\
\hline $\begin{array}{l}\text { Time between last } \\
\text { attack and kleptomania, } \\
\text { months }\end{array}$ & 48 & 36 & 12 & 24 & 36 & 2 \\
\hline Response to treatment & $\begin{array}{l}\text { recovered } \\
\text { (in } 2 \text { years) }\end{array}$ & $\begin{array}{l}\text { no } \\
\text { improvement }\end{array}$ & $\begin{array}{l}\text { no } \\
\text { improvement }\end{array}$ & $\begin{array}{l}\text { recovered } \\
\text { (in } 2 \text { years) }\end{array}$ & $\begin{array}{l}\text { no } \\
\text { improvement }\end{array}$ & $\begin{array}{l}\text { no } \\
\text { improvement }\end{array}$ \\
\hline $\begin{array}{l}\text { Neuropsychological } \\
\text { testing }\end{array}$ & $\begin{array}{l}\text { executive } \\
\text { dysfunction, } \\
\text { impairment } \\
\text { in visuospatial } \\
\text { functions }\end{array}$ & $\begin{array}{l}\text { executive } \\
\text { dysfunction, } \\
\text { verbal memory } \\
\text { impairment }\end{array}$ & $\begin{array}{l}\text { executive } \\
\text { dysfunction } \\
\text { only }\end{array}$ & $\begin{array}{l}\text { executive } \\
\text { dysfunction, } \\
\text { impairment in } \\
\text { verbal memory } \\
\text { and visuospatial } \\
\text { functions }\end{array}$ & $\begin{array}{l}\text { executive } \\
\text { dysfunction } \\
\text { only }\end{array}$ & $\begin{array}{l}\text { executive } \\
\text { dysfunction, } \\
\text { impairment } \\
\text { of verbal and } \\
\text { visual memory }\end{array}$ \\
\hline
\end{tabular}

$\mathrm{M}=$ Male; $\mathrm{F}$ = female; SSRI = selective serotonin reuptake inhibitor. A more detailed description of neuropsychological tests is available in Oktem-Tanör et al. [4] and Gündüz et al. [14].

4 had an MRI during a kleptomania episode. The MRI of case 4 performed after the onset of kleptomania showed only mild brain and brainstem atrophy and no parenchymal lesions.

The Expanded Disability Status Scores ranged between 2.0 and 4.0 at the time of diagnosis of kleptomania. All patients had received high-dose intravenous steroid treatment during their attacks, and all were under azathioprine treatment $(2.5 \mathrm{mg} / \mathrm{kg})$ for prophylaxis when they developed kleptomania.

The detailed neuropsychological and psychiatric evaluation of all patients was done within 2 months after the onset of kleptomania. This evaluation revealed executive dysfunction in all patients, impairment of visuospatial functions in 2 patients and impairment of verbal and/or visual memory in 3 patients. The psychiatric assessment did not reveal any other psychiatric diseases including impulse control or mood disorders. Among 4 patients (cases 1, 4, 5 and 6) who accepted treatment, 2 (cases 1 and 4) completely recovered with no recurrence of kleptomania, whereas 2 others (cases 5 and 6) did not show any improvement (table 1$)$.

\section{Index Case Report}

A 35-year-old male patient (case 4) with a 20-year history of Behçet's disease and 6-year history of neuro-Behçet's disease developed somnolence and aggressive behavior and recovered within days. Six months later, he was admitted again with dysarthria and left hemiparesis. The T2 and FLAIR weighted MRI sequences showed bilateral upper brainstem, diencephalon and basal ganglia lesions and cerebrospinal fluid analysis showed an increased number of neutrophils $\left(20 / \mathrm{mm}^{3}\right)$, protein concentration $(58 \mathrm{mg} / \mathrm{dl})$ and IgG index (0.8) with no oligoclonal bands. The neurological and radiological findings promptly ameliorated under pulse steroid treatment. Two years after the attack, he started having a strong urge to steal items and shoplifting and upon diagnosis of kleptomania, he was started on antipsychotics. Two weeks after the onset of kleptomania symptoms, neurological examination showed minimal left hemiparesis and dysarthria (Expanded Disability Status Scores: 3.0) and MRI showed only brain and brainstem atrophy with no parenchymal lesions. The neuropsychological evaluation 
at the same time showed impairment in executive functions, verbal memory and visuospatial functions. After 2 years of antipsychotic treatment (zuclopenthixol, $25 \mathrm{mg} /$ day), his kleptomania completely regressed with no recurrence in a follow-up period of 3 years.

\section{Discussion}

In this study, all neuro-Behçet's disease patients with kleptomania had executive dysfunction suggestive of frontal lobe involvement. However, the single patient with an MRI performed after the onset of kleptomania did not show any brain lesions and none of the patients had developed cortical lesions during their follow-up prior to the onset of kleptomania. Instead all patients had brainstem lesions. These results suggest that executive dysfunction might have emerged as a consequence of the disruption of the frontostriatal circuits at upper brainstem-midbrain level, as proposed previously [8].

Neuro-Behçet's disease with parenchymal involvement manifests as a syndrome of meningoencephalitis in the majority of cases [1]. Psychiatric symptoms often accompany the neurological findings. Apathy, acute psychosis, personality change and behavioral disorders have been reported so far and psychiatric symptoms may even precede an attack [4]. Cognitive impairment is also well observed and affects approximately $5 \%$ of patients with neuro-Behçet's disease [9]. These pathological findings were observed in all the 6 patients of this study.

Although kleptomania is frequently encountered in patients with psychiatric disorders, isolated kleptomania is a relatively rare condition [5]. Impulse control disorders can be a part of many psychiatric diseases, like schizophrenia, drug addiction or mood disorders. Single case reports of kleptomania with an organic basis, particularly in association with encephalitis, subarachnoidal hemorrhage, frontal lobe tumors and head trauma have been reported [10-12]. The onset of kleptomania of psychological origin is generally in late puberty, and women are affected more than men, whereas kleptomania with an organic etiology has been reported to develop at any age or gender depending on the character of the underlying brain disorder [1013]. Our patients were mostly middle-aged men as many patients with neuro-Behçet's disease are, suggesting that their kleptomania findings were of organic rather than psychological origin. Moreover, in contrast with kleptomania of purely psychological origin, our neuro-Behçet's disease patients with kleptomania did not show any comorbid psychiatric disorders. Also, all the patients had neuro-Behçet's disease for several years and developed brain lesions and neurological disability, all indicating that kleptomania was of organic origin. Notably, kleptomania patients do not show deficits on neuropsychological testing, although severe kleptomania cases may have impaired executive functioning indicating a link between frontal lobe syndrome and kleptomania [7] as in these 6 cases, thus further confirming this association.

It could be argued that kleptomania developed in these patients long after the last neuro-Behçet's disease attack, while they were under long-term immunosuppressive treatment with no neurological problems. The long-term treatment could explain why no brain lesions were seen on the MRI done during the kleptomania episodes. Apparently, kleptomania is not the consequence of any single parenchymal lesion but presumably develops due to accumulative effects of long-term neurodegeneration. This view is supported by the presence of severe neuropsychological impairment observed in many reported neuro-Behçet's disease patients in clinical remission with normal MRIs $[4,14,15]$. Likewise, case 4 reported in this study was in clinical remission, had significant neuropsychological impairment and did not show any parenchymal lesions on MRI.

One limitation of our study was that the diagnosis of kleptomania was based on the complaints of patients or family members and no detailed psychiatric evaluation had been performed before the onset of kleptomania. Hence, we could not entirely rule out the possibility that our patients had kleptomania previously.

\section{Conclusion}

The 6 kleptomania patients had developed a frontal lobe syndrome. They also showed executive dysfunction and brainstem lesions before the onset of kleptomania. Further, this study showed that kleptomania may occasionally emerge during the clinical course of neuro-Behçet's disease. Whether disinhibition and impulse control dysfunction caused by executive function impairment may have initiated kleptomania symptoms remains to be elucidated.

References

Akman-Demir G, Serdaroğlu P, Tasci B: Clinical patterns of neurological involvement in Behçet's disease: evaluation of 200 patients. The Neuro-Behçet Study Group. Brain 1999; 122:2171-2182.

-2 Erbilen E, Albayrak S, Gulcan E, et al: Acute coronary stenosis in a young man with Behçet's syndrome. Med Princ Pract 2008; 17: 157-160. 
3 Pekiner FN, Aytugar E, Demirel GY, et al: HLA-A, B (class I) and HLA-DR, DQ (class II) antigens in Turkish patients with recurrent aphthous ulceration and Behçet's disease. Med Princ Pract 2013, E-pub ahead of print. DOI: $10.1159 / 000348366$.

4 Oktem-Tanör O, Baykan-Kurt B, Gürvit IH, et al: Neuropsychological follow-up of 12 patients with neuro-Behçet disease. J Neurol 1999;246:113-119.

5 Marazziti D, Mungai F, Giannotti D, et al: Kleptomania in impulse control disorders, obsessive-compulsive disorder, and bipolar spectrum disorder: clinical and therapeutic implications. Curr Psychiatry Rep 2003;5: 36-40.
6 Dell'Osso B, Altamura AC, Allen A, et al: Epidemiologic and clinical updates on impulse control disorders: a critical review. Eur Arch Psychiatry Clin Neurosci 2006;256:464-475.

7 Grant JE, Odlaug BL, Wozniak JR: Neuropsychological functioning in kleptomania. Behav Res Ther 2007;45:1663-1670.

8 Winn P: Frontal syndrome as a consequence of lesions in the pedunculopontine tegmental nucleus: a short theoretical review. Brain Res Bull 1998;47:551-563.

9 Akman-Demir G, Saip S, Siva A: Behçet's disease. Curr Treat Options Neurol 2011;13: 290-310.

10 Grant JE, Odlaug BL, Kim SW: Kleptomania: clinical characteristics and relationship to substance use disorders. Am J Drug Alcohol Abuse 2010;36:291-295.

11 Aizer A, Lowengrub K, Dannon PN: Kleptomania after head trauma: two case reports and combination treatment strategies. Clin Neuropharmacol 2004;27:211-215.
12 Gürlek Yüksel E, Taşkin EO, Yilmaz Ovali G, et al: Case report: kleptomania and other psychiatric symptoms after carbon monoxide intoxication. Turk Psikiyatri Derg 2007;18:80-86.

13 Goldman MJ: Kleptomania: making sense of the nonsensical. Am J Psychiatry 1991;148: 986-996.

14 Gündüz T, Emir Ö, Kürtüncü M, et al: Cognitive impairment in neuro-Behçet's disease and multiple sclerosis: a comparative study. Int J Neurosci 2012;122:650-656.

15 Zayed H, Effat D, Nawito Z, et al: Silent central nervous system involvement in Egyptian Behçet's disease patients: clinical, psychiatric, and neuroimaging evaluation. Clin Rheumatol 2011;30:1173-1180. 